\title{
Characterization and prognostic significance of mortalin, Bcl-2 and Bax in intrahepatic cholangiocarcinoma
}

\author{
QIANG KANG $^{1 *}$, HAO ZOU $^{1 *}$, XUAN YANG $^{2 *}$, JIA-BIN CAI $^{2}$, LI-XIN LIU ${ }^{1}$, \\ NAN XIE $^{1,2}$, LIAN-MIN WANG ${ }^{1}$, YUE-HUA LI ${ }^{1}$ and XIAO-WEN ZHANG ${ }^{1}$ \\ ${ }^{1}$ Department of Hepatobiliary Surgery, The Second Affiliated Hospital, Kunming Medical University, Kunming, \\ Yunnan 650105; ${ }^{2}$ Liver Cancer Institute, Zhongshan Hospital, Fudan University, Shanghai 200032, P.R. China
}

Received May 4, 2017; Accepted November 10, 2017

DOI: $10.3892 / \mathrm{ol} .2017 .7570$

\begin{abstract}
Intrahepatic cholangiocarcinoma (ICC) is an aggressive type of cancer, and its incidence and mortality rates are increasing worldwide. Mortalin is a highly conserved chaperone protein involved in multiple pathological and physiological processes, including anti-apoptosis, carcinogenesis and metastasis. The Bcl-2 family of proteins can be divided into pro-survival and pro-apoptotic members, including B-cell lymphoma 2 (Bcl-2) and Bcl-2-like protein 4 (Bax). The aim of the present study was to investigate the association between mortalin, Bcl-2 and Bax, as well as the prognostic significance of the combined expression of mortalin, Bcl-2 and Bax in ICC. Immunohistochemistry was used to determine the expression of mortalin, Bcl-2 and Bax in 116 ICC samples and to assess the association between expression of 3 markers and clinicopathological features of ICC patients. This revealed that ICC tumor tissues overexpressed mortalin and Bcl-2 and exhibited low expression of Bax in ICC tumor tissues compared with that in corresponding peritumoral samples. According to Pearson's correlation coefficient analysis, high expression of mortalin in ICC was positively correlated with Bcl-2 expression and negatively correlated with Bax expression. Furthermore, multiple linear regression analysis demonstrated that mortalin was
\end{abstract}

Correspondence to: Dr Xiao-Wen Zhang or Dr Yue-Hua Li, Department of Hepatobiliary Surgery, The Second Affiliated Hospital, Kunming Medical University, 374 Dian Mian Road, Kunming, Yunnan 650105, P.R. China

E-mail: zhangxiaowenlu@163.com

E-mail: 13211664132@163.com

${ }^{*}$ Contributed equally

Abbreviations: ICC, intrahepatic cholangiocarcinoma; Bcl-2, B-cell lymphoma 2; Bax, Bcl-2-like protein 4; IHC, immunohistochemistry; OS, overall survival; HCC, hepatocellular carcinoma; TNM, tumor-node-metastasis; GGT, $\gamma$-glutamyl transpeptidase; CEA, carcinoembryonic antigen; CA19-9, carbohydrate antigen 19-9

Key words: intrahepatic cholangiocarcinoma, mortalin, B-cell lymphoma 2, Bcl-2-like protein 4, prognosis positively associated with Bcl-2, but not with Bax, in patients with ICC. Patients with ICC exhibiting high expression of mortalin/Bcl-2 or low expression of Bax were closely associated with a malignant ICC phenotype, a relatively low overall survival rate and a high recurrence rate. Multivariate analysis indicated that mortalin and Bcl-2 were independent prognostic indicators for ICC patients. Meanwhile, the concomitant overexpression of mortalin and Bcl-2 and the low expression of Bax were independent markers for predicting a relatively poor prognosis of ICC. The overexpression of mortalin and $\mathrm{Bcl}-2$ and/or the low expression of Bax are implicated in the anti-apoptotic effect and tumor progression of ICC. Mortalin or Bcl-2, or a combination of mortalin, Bcl-2 and Bax may be used to predict the prognosis of ICC, as well as potential therapeutic targets.

\section{Introduction}

Intrahepatic cholangiocarcinoma (ICC) arises from the bile epithelial cells of the intrahepatic second-degree bile tracts (1). ICC is the second most common primary liver cancer following hepatocellular carcinoma (HCC) and accounts for $10-15 \%$ of all primary liver cancer cases (2). In recent decades, the incidence rate for ICC has increased worldwide $(3,4)$. Despite the existence of diverse treatment strategies, including curative surgical resection, pre-operative portal vein embolization, trans-arterial chemoembolization and liver transplantation, the prognosis for patients with ICC remains unsatisfactory $(5,6)$. Frequent recurrence and aggressive metastasis limit the success of postoperative therapies and the overall prognosis (7). Therefore, a better comprehension of the potential molecular mechanisms behind ICC is urgently required in order to investigate potential prognostic factors and to improve the overall survival (OS) rate.

The B-cell lymphoma 2 gene (Bcl-2) (8) is part of a family of proteins whose main function is their involvement in the initiation phase of the intrinsic pathways of apoptosis (9). Bcl-2 has been demonstrated to be associated with apoptosis (10), which can be induced via various stimuli, including lipid peroxidation, glucose deprivation and growth factor deprivation (8). High expression of $\mathrm{Bcl}-2$ has been indicated to protect against apoptosis (11). A number of clinical studies suggested that the overexpression of $\mathrm{Bcl}-2$ was associated with a relatively poor 
prognosis in a number of malignant tumors types, including breast cancer and pancreatic carcinoma $(12,13)$. Bcl-2-like protein 4 (Bax), a pro-apoptotic protein of the Bcl-2 family of proteins, has been demonstrated to be directly regulated by the tumor suppressor cellular antigen p53 (p53) (14). Multiple studies have demonstrated that Bax could strongly facilitate mitochondrial membrane permeabilization and the activation of nucleases and caspases. This can result in irreversible damage to the mitochondria and accelerated programmed cell death $(15,16)$.

Mortalin (also known as glucose-regulated protein 75) is a member of the heat shock protein 70 family, which was originally identified in the cytoplasm of mouse embryonic fibroblasts (17). Research suggests that the expression of mortalin is associated with a number of biological processes, including intracellular trafficking, cell proliferation and apoptosis, protein localization, antigen processing, muscle activity and regulation of p53 $(18,19)$. Previous studies have demonstrated that mortalin interacts directly with Bcl-2 and can indirectly regulate Bax via p53 (20,21). Recent studies have demonstrated that mortalin is overexpressed in numerous types of cancerous tumors, and is involved in a multitude of pathological processes that promote tumor carcinogenesis and progression (22-24).

The aim of the present study was to investigate the expression of mortalin, Bcl-2 and Bax in ICC, and the association between these 3 markers and the clinicopathological features of patients with ICC. The associations between the expression of these markers was analyzed, and finally, the prognostic significance of mortalin, Bcl-2 and Bax in patients with ICC was statistically evaluated.

\section{Materials and methods}

Patients and follow-up. Fresh ICC tumor tissues and their corresponding peritumoral tissues were obtained from 116 consecutive patients (mean age, 59.38; range 30-81) who underwent curative resection between February 1998 and December 2006 at the Liver Cancer Institute (Zhongshan Hospital, Shanghai, China). Curative resection was defined as per Huang et al (25). Liver function was evaluated according to the Child-Pugh scoring system (26). ICC diagnosis was based on the criteria outlined by the World Health Organization (27). Tumor differentiation was based on the classification proposed by Edmondson and Steiner (27). The clinical classification of tumors was performed according to the 7 th edition of the tumor-node-metastasis (TNM) classification system of the International Union Against Cancer (28). The detailed clinicopathological features recorded are provided in Table I. The following patient exclusion criteria were applied: Failure of important organs, including the heart, lungs, kidneys and brain, intolerance to surgery, distant organ metastasis, lymph node involvement beyond the hepatoduodenal ligament, hilar or caval lymph nodes, preoperative chemotherapy or radiotherapy and preoperative liver treatment (arterial chemoembolization, radiofrequency ablation or percutaneous ethanol injection). Ethical approval was obtained from the Zhongshan Hospital Research Ethics Committee and each patient provided written informed consent. All incorporated ICC patients had undergone regular follow-ups and full clinicopathological data was available for prognostic analysis. During follow-up, abdominal Doppler ultrasonography, a physical examination and serological tests were performed every 1-2 months postoperatively during the first 2 years, then every 3-4 months from years 2-5 and every 6 months thereafter. For patients with suspected recurrence of ICC, computed tomography or magnetic resonance was used for confirmation. Patients with recurrence were treated by arterial chemoembolization, radiofrequency ablation and percutaneous ethanol injection or a second liver resection depending on the tumor number, location and size, the number of affected lymph nodes and the extent of distant metastasis. OS time was defined as the time between the date of original surgery until the end of follow-up (December 31, 2016) or the event of mortality from any cause. The recurrence time was defined as the duration between the date of original surgery to the time of recurrence. The median follow-up time was 31.5 months (range, 4-120 months).

Tissue microarray and immunohistochemistry (IHC). Tissue microarrays were constructed and IHC was performed as described in our previous studies $(25,29)$. Rabbit anti-human mortalin monoclonal antibody (cat. no. 3593, dilution 1:100; Cell Signaling Technology, Inc., Danvers, MA, USA), mouse anti-human Bcl-2 monoclonal antibody (cat. no. ab182858, dilution 1:400) and mouse anti-human Bax monoclonal antibody (cat.no. ab77566; dilution 1:400) (both from Abcam, Cambridge, UK) were used to detect the expression of mortalin, Bcl-2 and Bax in ICC tissues, respectively. Two independent pathologists, who were blinded to patient clinicopathological characteristics, analyzed the IHC staining using an optical microscope. The scoring criteria for the determination of mortalin, Bcl-2 and Bax staining intensities were defined as follows: 3, strong (deep-brown staining); 2, moderate (medium-brown staining); 1 , weak (light-brown staining); and 0 , negative (absence of brown staining). The mean area of positive staining was scored as follows: $0,0-30 \% ; 1,31-60 \%$; and $2 \%,>60 \%$. Total staining score (intensity + mean area) $\geq 2.0$ was considered to indicate high expression, and total scores $<2.0$ were considered to indicate low expression.

Statistical analysis. Statistical analysis was performed using SPSS, version 21.0 (IBM Corp., Armonk, NY, USA). Data are presented as the mean \pm standard deviation. Continuous data were analyzed using Student's t-tests. The correlations between mortalin, Bcl-2 and Bax protein levels were assessed using Pearson's correlation coefficient and multiple linear regression analysis. The Kaplan-Meier method and the log-rank test were used to calculate the OS and cumulative recurrence rates. Cox's proportional hazards regression model was used to investigate potential independent prognostic factors. All tests were two-tailed. $\mathrm{P}<0.05$ was considered to indicate a statistically significant difference.

\section{Results}

Expression of mortalin, Bcl-2 and Bax in ICC patients. Hematoxylin and eosin staining was used to identify primary ICC, and the expression of mortalin, Bcl-2 and Bax protein was detected using IHC of tissues from 116 patients with ICC. Mortalin (Fig. 1A) and Bcl-2 (Fig. 1B) expression was exhibited 
Table I. Association of mortalin, Bax or Bcl-2 expression with clinicopathological characteristics in 116 patients with intrahepatic cholangiocarcinoma.

\begin{tabular}{|c|c|c|c|c|c|c|c|}
\hline Variable & Number & $\begin{array}{l}\text { Mortalin staining } \\
\text { (\% total area) }\end{array}$ & P-value & $\begin{array}{l}\text { Bcl-2 staining } \\
\text { (\% total area) }\end{array}$ & P-value & $\begin{array}{l}\text { Bax staining } \\
(\% \text { total area) }\end{array}$ & P-value \\
\hline \multicolumn{8}{|l|}{ Age, years } \\
\hline$\geq 53$ & 60 & $47.7 \pm 23.9$ & \multirow[t]{2}{*}{ NS } & $53.4 \pm 22.9$ & \multirow[t]{2}{*}{0.029} & $21.1 \pm 14.5$ & \multirow[t]{2}{*}{ NS } \\
\hline$<53$ & 56 & $48.4 \pm 22.8$ & & $44.9 \pm 20.7$ & & $21.7 \pm 16.4$ & \\
\hline \multicolumn{8}{|l|}{ Sex } \\
\hline Male & 50 & $51.2 \pm 24.5$ & \multirow[t]{2}{*}{ NS } & $51.7 \pm 21.9$ & \multirow[t]{2}{*}{ NS } & $20.6 \pm 12.2$ & \multirow[t]{2}{*}{ NS } \\
\hline Female & 66 & $45.3 \pm 22.3$ & & $47.4 \pm 22.7$ & & $22.5 \pm 17.6$ & \\
\hline \multicolumn{8}{|l|}{ GGT, U/l } \\
\hline$\geq 37$ & 60 & $47.5 \pm 23.2$ & \multirow[t]{2}{*}{ NS } & $49.9 \pm 22.4$ & \multirow[t]{2}{*}{ NS } & $22.0 \pm 15.9$ & \multirow[t]{2}{*}{ NS } \\
\hline$<37$ & 56 & $48.6 \pm 23.6$ & & $47.9 \pm 22.6$ & & $21.4 \pm 15.2$ & \\
\hline \multicolumn{8}{|l|}{ CEA, ng/ml } \\
\hline$\geq 5$ & 71 & $52.5 \pm 21.4$ & \multirow[t]{2}{*}{ NS } & $49.9 \pm 22.3$ & \multirow[t]{2}{*}{ NS } & $22.0 \pm 15.9$ & \multirow[t]{2}{*}{ NS } \\
\hline$<5$ & 45 & $45.2 \pm 24.2$ & & $48.5 \pm 22.6$ & & $21.4 \pm 15.2$ & \\
\hline \multicolumn{8}{|c|}{ CA19-9, ng/ml } \\
\hline$>75$ & 70 & $47.2 \pm 23.9$ & \multirow[t]{2}{*}{ NS } & $47.9 \pm 22.7$ & \multirow[t]{2}{*}{ NS } & $19.3 \pm 14.5$ & \multirow[t]{2}{*}{0.039} \\
\hline$\leq 75$ & 46 & $49.4 \pm 22.5$ & & $50.6 \pm 22.1$ & & $25.3 \pm 16.2$ & \\
\hline \multicolumn{8}{|c|}{ Liver cirrhosis } \\
\hline Yes & 47 & $52.2 \pm 22.8$ & \multirow[t]{2}{*}{0.018} & $50.2 \pm 22.6$ & \multirow[t]{2}{*}{ NS } & $22.8 \pm 17.5$ & \multirow[t]{2}{*}{ NS } \\
\hline No & 69 & $41.9 \pm 22.9$ & & $47.3 \pm 22.3$ & & $20.8 \pm 13.9$ & \\
\hline \multicolumn{8}{|c|}{ Tumor encapsulation } \\
\hline No & 96 & $49.1 \pm 22.6$ & \multirow[t]{2}{*}{ NS } & $49.3 \pm 22.9$ & \multirow[t]{2}{*}{ NS } & $21.8 \pm 15.1$ & NS \\
\hline Yes & 20 & $43.1 \pm 21.9$ & & $47.5 \pm 20.3$ & & $20.8 \pm 17.1$ & \\
\hline Lymphatic 1 & & & & & & & \\
\hline Yes & 28 & $54.2 \pm 22.8$ & 0.009 & $52.5 \pm 22.7$ & NS & $19.7 \pm 11.8$ & NS \\
\hline No & 88 & $45.1 \pm 23.1$ & & $47.3 \pm 22.2$ & & $22.4 \pm 16.8$ & \\
\hline Tumor num & & & & & & & \\
\hline Multiple & 10 & $62.9 \pm 20.9$ & 0.034 & $67.8 \pm 17.9$ & 0.005 & $20.8 \pm 15.5$ & NS \\
\hline Solitary & 106 & $46.6 \pm 23.1$ & & $47.2 \pm 22.1$ & & $21.6 \pm 15.5$ & \\
\hline Tumor diam & & & & & & & \\
\hline$\geq 5$ & 25 & $47.1 \pm 22.5$ & NS & $48.9 \pm 22.7$ & NS & $26.1 \pm 18.3$ & 0.013 \\
\hline$<5$ & 91 & $48.3 \pm 26.7$ & & $49.5 \pm 21.5$ & & $19.5 \pm 14.5$ & \\
\hline Tumor diffe & & & & & & & \\
\hline Grade 3/4 & 58 & $53.1 \pm 24.6$ & 0.017 & $53.4 \pm 21.4$ & 0.042 & $21.0 \pm 15.4$ & NS \\
\hline Grade $1 / 2$ & 58 & $42.9 \pm 20.9$ & & $45.1 \pm 22.2$ & & $21.9 \pm 15.6$ & \\
\hline TNM stage & & & & & & & \\
\hline III/IV & 32 & $52.9 \pm 23.5$ & 0.047 & $55.1 \pm 21.6$ & 0.012 & $17.4 \pm 10.1$ & 0.021 \\
\hline $\mathrm{I} / \mathrm{II}$ & 84 & $44.3 \pm 22.6$ & & $44.8 \pm 21.5$ & & $24.4 \pm 17.9$ & \\
\hline
\end{tabular}

All values are presented as mean \pm standard deviation. Bcl-2, B-cell lymphoma 2; Bax, Bcl-2-like protein 4; CA, carbohydrate antigen; GGT, $\gamma$-glutamyl transpeptidase; NS, not significant; CEA, carcinoembryonic antigen; TNM, tumor-node-metastasis.

in the cell cytoplasm of ICC tumor cells. However, Bax expression was exhibited in the cell cytoplasm of peritumoral bile epithelial cells (Fig. 1C).

A total of 60 ICC tumor tissues expressed high levels of mortalin (51.7\%). The expression of mortalin was higher in ICC tissues than in adjacent peritumoral liver tissues (3.61 \pm 0.88 vs. $1.12 \pm 0.84, \mathrm{P}<0.001$; Fig. $1 \mathrm{~A}$ and D). Consistent with a previous study (29), high expression of mortalin was significantly associated with liver cirrhosis $(\mathrm{P}=0.018)$, lymphatic metastasis $(\mathrm{P}=0.009)$, tumor differentiation $(\mathrm{P}=0.017)$, tumor number $(\mathrm{P}=0.034)$ and $\mathrm{TNM}$ stage $(\mathrm{P}=0.047)$ (Table I). However, none of the other clinical characteristics, including age, sex, serum $\gamma$-glutamyl transpeptidase (GGT), carcinoembryonic antigen (CEA), carbohydrate antigen 19-9 (CA19-9), tumor encapsulation or tumor diameter were associated with mortalin expression. 

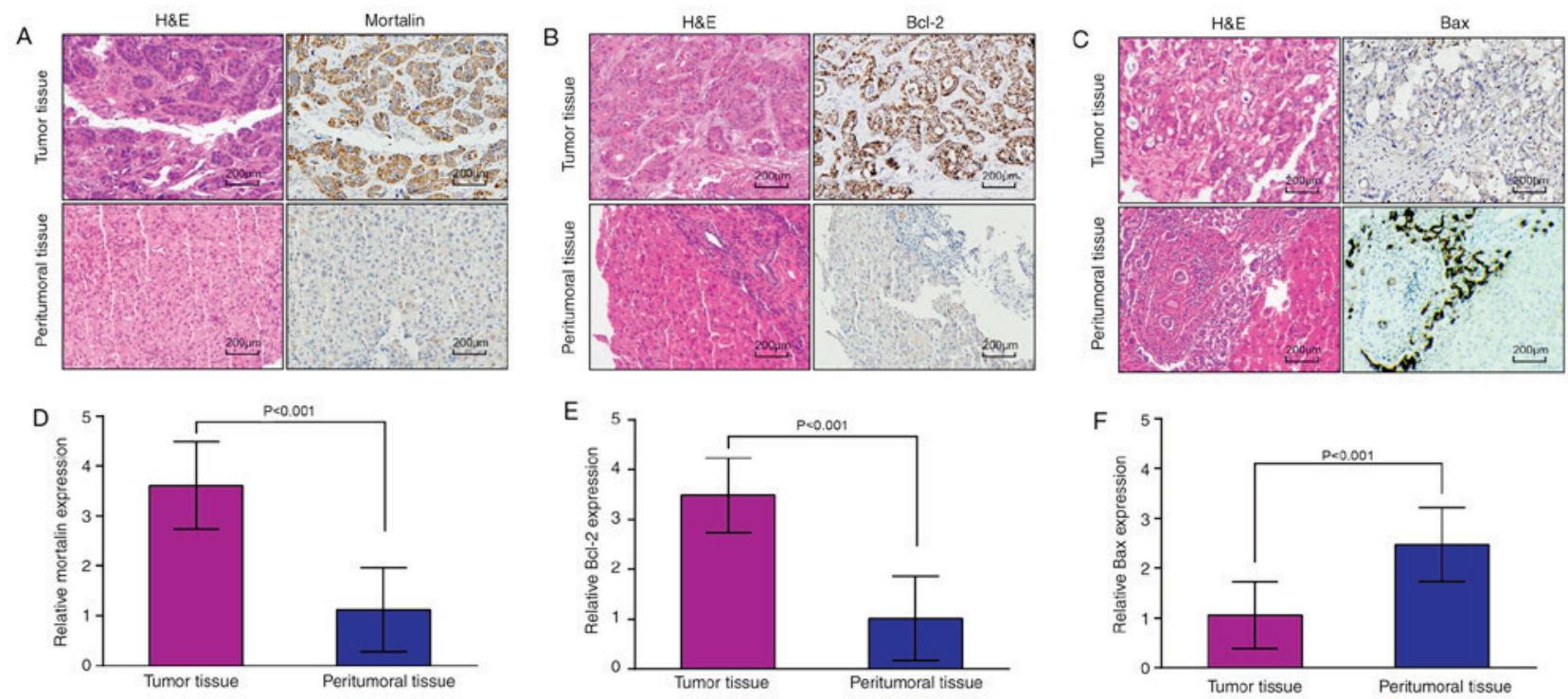

Figure 1. Expression of mortalin, Bcl-2 and Bax in ICC tissues and peritumoral samples. Representative images for H\&E staining, and (A) mortalin, (B) Bcl-2 and (C) Bax immunohistochemical staining in tumor and peritumoral samples (scale bars, $200 \mu \mathrm{m}$ ). (D) A histogram demonstrating that the expression of mortalin in ICC tissues was high compared with peritumoral tissues $(\mathrm{P}<0.001)$. (E) The expression of $\mathrm{Bcl}-2$ in ICC tissues was high compared with peritumoral tissues $(\mathrm{P}<0.001)$; and $(\mathrm{F})$ that the expression of $\mathrm{Bax}$ in tumor samples was significantly lower than that in the peritumoral samples $(\mathrm{P}<0.001)$. Bcl-2, B-cell lymphoma 2; Bax, Bcl-2-like protein 4; ICC, intrahepatic cholangiocarcinoma; H\&E, hematoxylin and eosin.

A
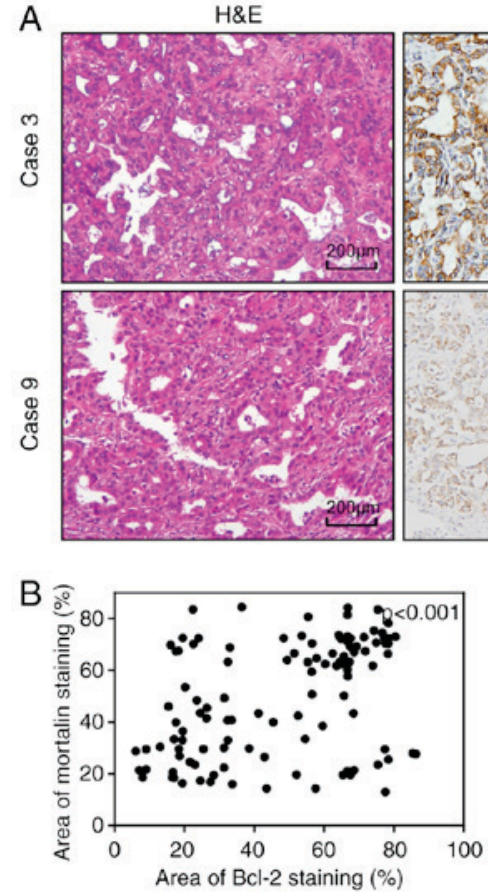

Mortalin

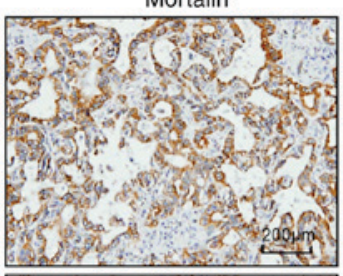

$200 \mu \mathrm{m}$
$\mathrm{Bcl}-2$

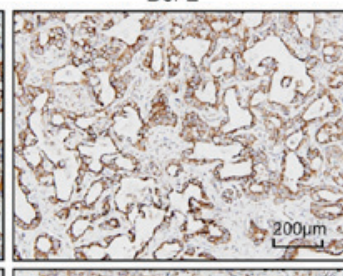

Bax

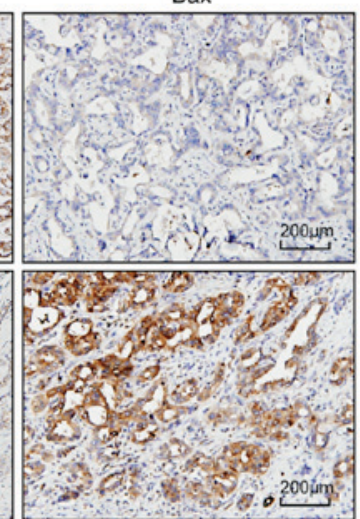

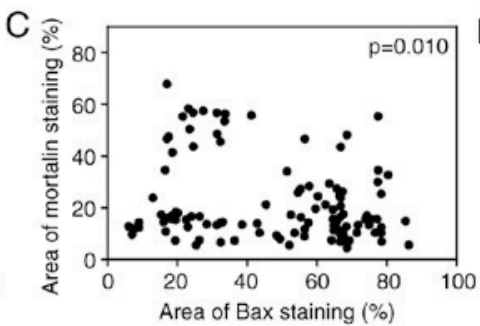

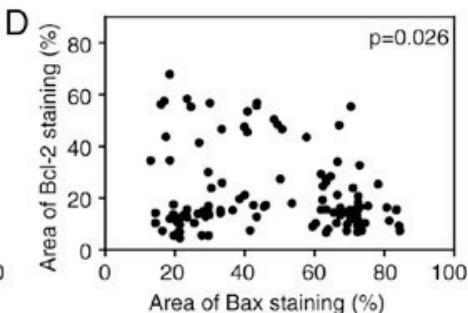

Figure 2. Associations between mortalin, Bcl-2 and Bax expression in ICC tumor samples. (A) Representative staining images demonstrating high moratlin and Bcl-2 expression and low Bax expression tissue (case 3), and low mortalin and Bcl-2 expression and low Bax expression tissue (case 9) (scale bars, $200 \mu$ m). Positive correlations were detected between (B) mortalin and Bcl-2 expression in ICC tissues ( $\mathrm{r}=0.398, \mathrm{P}<0.001)$; (C) between mortalin and Bax expression $(\mathrm{r}=-0.238, \mathrm{P}=0.010)$ and $(\mathrm{D})$ between $\mathrm{Bcl}-2$ and Bax expression ( $\mathrm{r}=-0.207, \mathrm{P}=0.026)$. Bcl-2, B-cell lymphoma 2; Bax, Bcl-2-like protein 4; ICC, intrahepatic cholangiocarcinoma; $\mathrm{H} \& \mathrm{E}$, hematoxylin and eosin.

High Bcl-2 expression was exhibited in 61 ICC tumor tissues (52.6\%). Higher levels of Bcl-2 expression were detected in tumor tissues compared with the levels detected in peritumoral tissues $(3.48 \pm 0.75$ vs. $1.02 \pm 0.84, \mathrm{P}<0.001$; Fig. $1 \mathrm{~B}$ and $\mathrm{E})$. Patients with high $\mathrm{Bcl}-2$ expression were older $(\mathrm{P}=0.029)$, had multiple tumors $(\mathrm{P}=0.005)$, low tumor differentiation $(\mathrm{P}=0.017)$ and a high TNM stage $(\mathrm{P}=0.047)$ compared with patients exhibiting low Bcl-2 expression expression (Table I).

A total of 18 ICC tissues expressed high levels of Bax (15.5\%). Expression of Bax was evidently lower in ICC tissues compared with the peritumoral tissues $(1.06 \pm 0.67$ vs. $2.54 \pm 0.78, \mathrm{P}<0.001$; Fig. $1 \mathrm{C}$ and F). Serum CA19-9 was significantly associated with low Bax expression $(\mathrm{P}=0.039)$, 
Table II. Univariate and multivariate Cox regression analysis of factors associated with overall survival rate and cumulative recurrence rate.

\begin{tabular}{|c|c|c|c|c|c|c|}
\hline \multirow[b]{3}{*}{ Variable } & \multicolumn{3}{|c|}{ Overall survival } & \multicolumn{3}{|c|}{ Cumulative recurrence } \\
\hline & \multirow{2}{*}{$\begin{array}{l}\text { Univariate } \\
\text { P-value }\end{array}$} & \multicolumn{2}{|c|}{ Multivariate } & \multirow{2}{*}{$\begin{array}{l}\text { Univariate } \\
\text { P-value }\end{array}$} & \multicolumn{2}{|l|}{ Multivariate } \\
\hline & & HR $(95 \% \mathrm{CI})$ & P-value & & HR $(95 \% \mathrm{CI})$ & P-value \\
\hline Age ( $<53$ vs. $\geq 53$ years) & 0.401 & & NA & 0.368 & & NA \\
\hline Sex (male vs. female) & 0.791 & & NA & 0.637 & & NA \\
\hline GGT (<37 vs. $\geq 37 \mathrm{U} / 1)$ & 0.602 & & NA & 0.101 & & NA \\
\hline CEA $(<5$ vs. $\geq 5 \mathrm{ng} / \mathrm{ml})$ & 0.398 & & NA & 0.332 & & NA \\
\hline Serum CA19-9 (<37 vs. $\geq 37 \mathrm{ng} / \mathrm{ml})$ & 0.189 & & NA & 0.064 & & NA \\
\hline Liver cirrhosis (no vs. yes) & 0.477 & & NA & 0.280 & & NA \\
\hline Tumor encapsulation (no vs. yes) & 0.191 & & NA & 0.067 & & NS \\
\hline Lymphatic metastasis (no vs. yes) & $<0.001$ & & NS & $<0.001$ & & NS \\
\hline TNM stage (I/II vs. III/IV) & $<0.001$ & $0.563(0.320-0.993)$ & 0.047 & $<0.001$ & $0.524(0.301-0.910)$ & 0.022 \\
\hline Tumor number (single vs. multiple) & $<0.001$ & & NS & 0.001 & & NS \\
\hline Tumor diameter $(<5$ vs. $\geq 5 \mathrm{~cm})$ & 0.152 & & NA & 0.098 & & NA \\
\hline Tumor differentiation (low vs. high) & $<0.001$ & $0.562(0.354-0.891)$ & 0.014 & $<0.001$ & $0.536(0.337-0.851)$ & 0.008 \\
\hline Mortalin staining (low vs. high) & $<0.001$ & $3.381(1.777-6.435)$ & $<0.001$ & $<0.001$ & $3.175(1.675-6.018)$ & $<0.001$ \\
\hline Bcl-2 staining (low vs. high) & 0.001 & $2.909(1.550-5.459)$ & 0.001 & $<0.001$ & $2.636(1.351-4.732)$ & 0.004 \\
\hline Bax staining (low vs. high) & 0.009 & & NS & 0.010 & & NS \\
\hline $\begin{array}{l}\text { Combination of mortalin, Bcl-2 and } \\
\text { Bax (group I vs. groups II/III) }\end{array}$ & 0.002 & $3.277(1.459-7.358)$ & 0.004 & 0.002 & $2.808(1.257-6.271)$ & 0.012 \\
\hline
\end{tabular}

aPatients were divided into 3 groups according to expression of mortalin, Bcl-2, and Bax. Group I ( $\mathrm{n}=41$ ) had low expression of Bax and high expression of mortalin and Bcl-2; group II ( $\mathrm{n}=14$ ) had high expression of Bax and low expression of mortalin and Bcl-2; and group III ( $\mathrm{n}=61$ ) includes all possible remaining combinations of the 3 markers. GGT, $\gamma$-glutamyl transpeptidase; CEA, carcinoembryonic antigen; CA19-9, carbohydrate antigen 19-9; TNM, tumor-node-metastasis; Bcl-2, B-cell lymphoma 2; Bax, Bcl-2-like protein 4; CI, confidence interval; HR, hazard ratio; NA, not adopted; NS, not significant.

tumor diameter $(\mathrm{P}=0.013)$ and $\mathrm{TNM}$ stage $(\mathrm{P}=0.021)$ (Table I).

Clinical association between the expression of mortalin and Bcl-2 or Bax in ICC patients. A correlation analysis of mortalin, Bcl-2 and Bax expression was performed on the basis of the IHC results. The expression levels of mortalin and $\mathrm{Bcl}-2$ protein levels were markedly increased in ICC tissues, whereas the expression level of Bax protein was significantly downregulated in tumor tissues. The high expression of mortalin was positively correlated with the expression of Bcl-2 (Fig. 2A), as indicated in a scatter plot of mortalin and Bcl-2 expression in Fig. 2B ( $\mathrm{r}=0.398, \mathrm{P}<0.001)$. However, high mortalin expression was negatively correlated with the expression of $\mathrm{Bax}(\mathrm{r}=-0.238, \mathrm{P}=0.010$; Fig. $2 \mathrm{C})$, and high Bcl-2 expression was also negatively correlated with the expression of Bax ( $r=-0.207$, $P=0.026$; Fig. 2D). Furthermore, multiple linear regression analysis also revealed that the expression of mortalin was positively associated with that of Bcl-2 ( $\mathrm{r}=0.425, \mathrm{P}<0.001)$ in ICC patients (data not shown). However, no significant association was detected for Bax $(\mathrm{P}=0.091)$ (data not shown).

Combined expression of mortalin, Bcl-2 and Bax is associated with poor prognosis in patients with ICC. Over the follow-up period, 83 patients suffered from ICC recurrence and 84 fatalities occurred. The 2- and 5-year OS rates for patients with ICC were 69.8 and $28.3 \%$, respectively, and the 2- and 5-year cumulative recurrence rates were 38.7 and $72.4 \%$, respectively. Univariate analysis demonstrated that lymphatic metastasis, tumor differentiation, tumor number and TNM stage were predictors of OS and cumulative recurrence (Table II). Other clinicopathological characteristics, such as age, sex, serum GGT, serum CEA, serum CA9-9, liver cirrhosis, tumor encapsulation and max diameter had no prognostic significance in terms of the OS or cumulative recurrence rates (Table II).

The expression of mortalin, $\mathrm{Bcl}-2$ and $\mathrm{Bax}$ was also associated with OS and cumulative recurrence rates. As illustrated in Fig. 3A-C, the expression of the three proteins in the ICC tumor tissues demonstrated considerable heterogeneity. The 2- and 5-year OS rates in the high mortalin expression group were significantly lower than those in the low mortalin expression group (51.0 vs. $85.7 \%$ and 18.3 vs. $41.1 \%$, respectively; Fig. 3D). The corresponding cumulative recurrence rates in the high mortalin expression group were significantly higher than those in the low mortalin expression group (53.3 vs. $21.4 \%$ and 85.0 vs. $62.5 \%$, respectively; Fig. 3E). The 2- and 5-year OS rates in the high Bcl-2 expression group were significantly lower compared with those in the low Bcl-2 expression group (55.7 vs. $80.0 \%$ and 18.1 vs. $43.6 \%$, respectively; Fig. 3F). The 

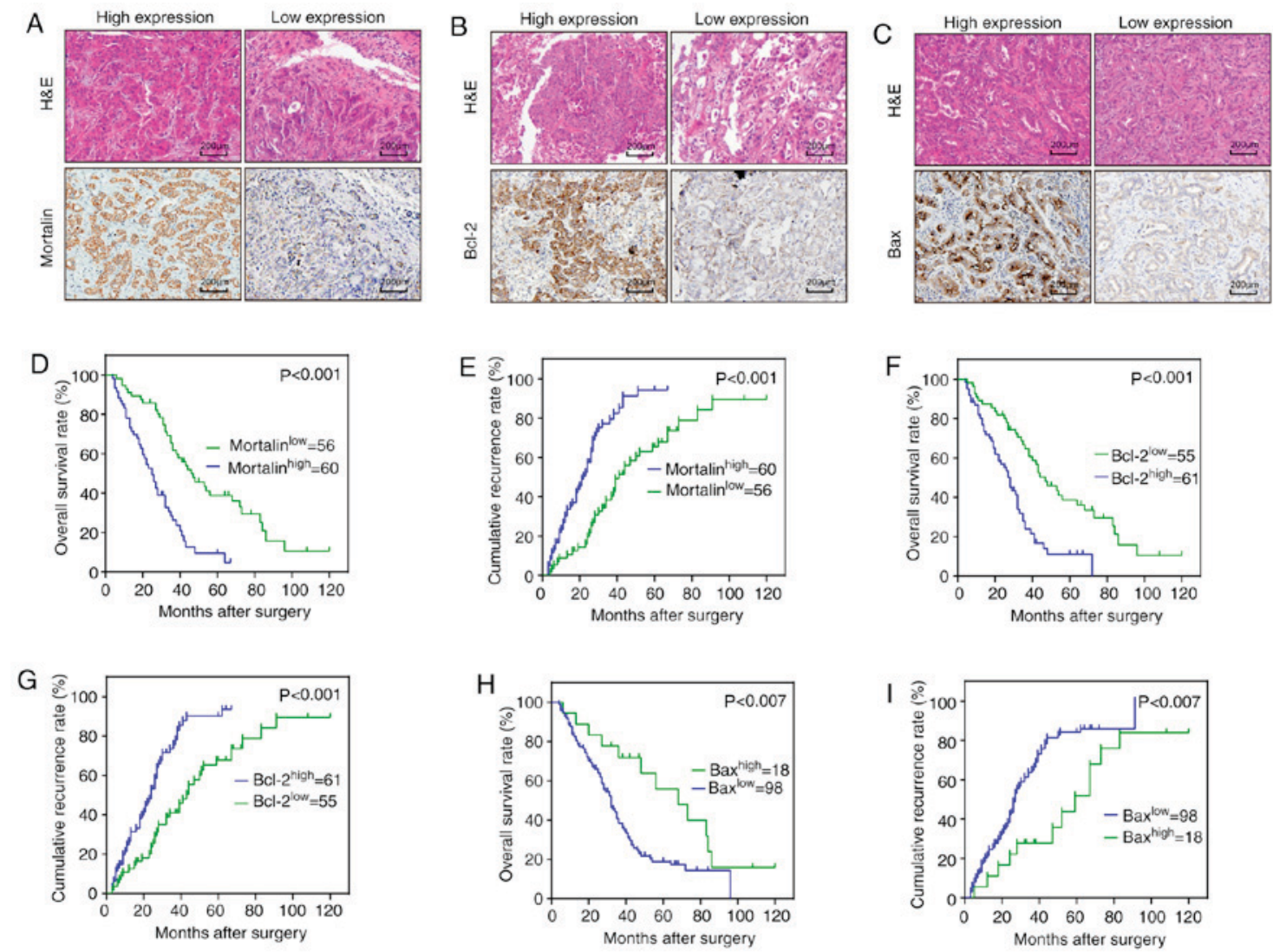

Figure 3. Kaplan-Meier analysis and log-rank test analysis of prognostic significance. Representative images of H\&E and immunohistochemical staining for (A) mortalin, (B) Bcl-2 and (C) Bax in ICC samples (scale bars, $200 \mu \mathrm{m}$ ). ICC patients with high mortalin expression had a poorer prognosis according to (D) overall survival and (E) cumulative recurrence compared with those exhibiting low mortalin expression. ICC patients exhibiting high Bcl-2 expression had a poorer prognosis according to $(\mathrm{F})$ overall survival and $(\mathrm{G})$ cumulative recurrence compared with those exhibiting low Bcl-2 expression. ICC patients with low Bax expression had a poorer prognosis according to $(\mathrm{H})$ overall survival and (I) cumulative recurrence compared with those exhibiting high Bax expression. Bcl-2, B-cell lymphoma 2; Bax, Bcl-2-like protein 4; H\&E, hematoxylin and eosin; ICC, intrahepatic cholangiocarcinoma.
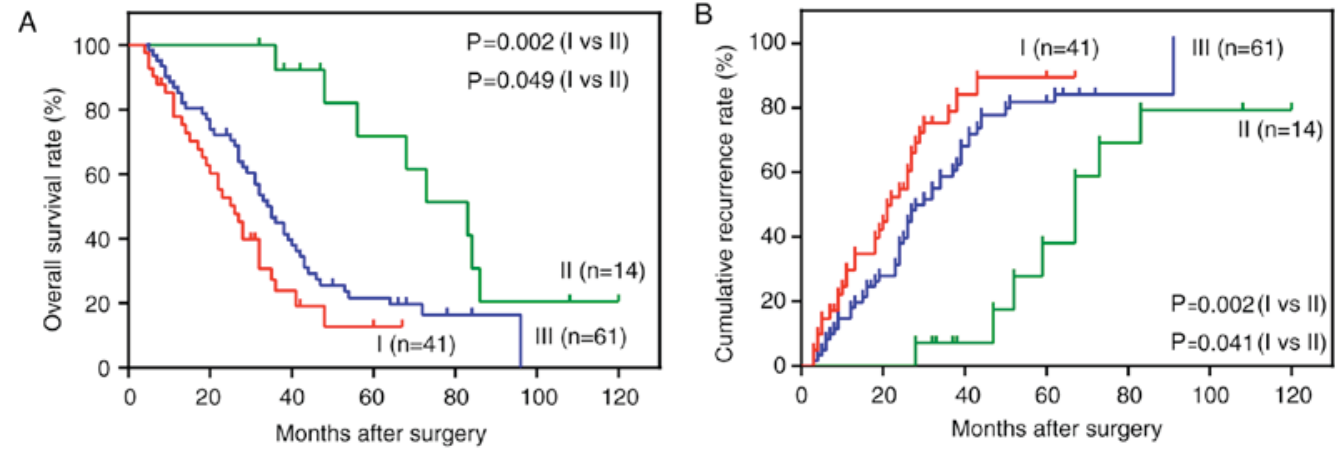

Figure 4. Combined expression of mortalin, Bcl-2 and Bax to predict ICC prognosis via Kaplan-Meier analysis. (A) Patients with ICC exhibiting high mortalin and Bcl-2 expression and low Bax expression had a relatively poor prognosis according to overall survival rates of the 3 subgroups: I, high mortalin and Bcl-2 expression and low Bax expression; II, low mortalin and Bcl-2 expression and high Bax expression; and III, all possible remaining combinations of expression of the 3 proteins. (B) Patients with ICC exhibiting high mortalin and Bcl-2 expression and low Bax expression were associated with the worst prognosis according to cumulative recurrence rates in the 3 subgroups. Bcl-2, B-cell lymphoma 2; Bax, Bcl-2-like protein 4; ICC, intrahepatic cholangiocarcinoma.

2- and 5-year cumulative recurrence rates in the high Bcl-2 expression group were significantly higher than those in the low Bcl-2 expression group (52.5 vs. $23.6 \%$ and 81.9 vs. $61.8 \%$, respectively; Fig. 3G). The postoperative 2- and 5-year OS rates for ICC patients were lower in the low Bax expression group than those in the high Bax expression group (66.3 vs. $88.3 \%$ and 17.3 vs. $44.4 \%$, respectively; Fig. $3 \mathrm{H}$ ), and the postoperative 2- and 5-year cumulative recurrence rates in the high Bax expression group were significantly higher than those in the low Bax expression group (22.2 vs. $41.8 \%$ and 55.6 vs. $84.7 \%$, respectively; Fig. 3I).

To investigate the combined effect of the expression of mortalin, Bcl-2 and Bax on the prognosis of patients with ICC, patient samples were divided into 3 subgroups: Group I $(n=41)$ exhibited low expression of Bax and high expression of mortalin and Bcl-2; group II ( $\mathrm{n}=14)$ exhibited high expression 
of Bax and low expression of mortalin and Bcl-2; and group III $(n=61)$ consisted of all remaining possible combinations of expression of the 3 proteins, including high expression of all 3 markers; low expression of all 3 markers; low expression of Bcl-2, and high expression of mortalin and Bax; high expression of mortalin, and low expression of Bcl-2 and Bax; high expression of $\mathrm{Bcl}-2$, and low expression of mortalin and Bax; low expression of mortalin, and high expression of Bcl-2 and Bax. Kaplan-Meier analysis demonstrated that the 2- and 5 -year OS rates in group I were significantly lower than those in groups II and III ( $\mathrm{P}<0.05$; Fig. 4A). The 2 - and 5-year cumulative recurrence rates in group I were significantly higher than those for groups II and III ( $\mathrm{P}<0.05$; Fig. 4B). The multivariate Cox proportional hazards model analysis demonstrated that mortalin, Bcl-2, tumor differentiation and TNM stage were independent prognostic indicators for OS rate and cumulative recurrence of ICC (Table II). Furthermore, the combination of overexpression of mortalin and $\mathrm{Bcl}-2$ and low expression of Bax was also an independent prognostic indicator for OS rate and cumulative recurrence (Table II).

\section{Discussion}

Mortalin was first reported by Wadhwa et al (17); it is encoded by the gene of heat shock protein family A (Hsp70) member 9 and is involved in multiple mitochondrial processes, including maintenance of mitochondrial protein integrity, biogenesis, energy metabolism and translocation of cytosolic protein (20). Overexpression of mortalin has been detected in numerous types of malignant tumor (22-24). In the present study, it was confirmed that the expression of mortalin was significantly increased in ICC tissues compared with corresponding peritumoral tissues. Recent studies have demonstrated that high levels of mortalin expression are associated with a relatively poor prognosis in pancreatic cancer (23), non-small cell lung cancer (24) and hepatocellular carcinoma (30). The present study demonstrated that the expression of mortalin was an independent predictor of OS rate and cumulative recurrence in patients with ICC, which is consistent with previous research (29). Mortalin has been suggested to be a more efficient index than lymph node metastasis for evaluating the prognosis of gastric cancer patients (31). Previous studies have indicated that mortalin may interact with apoptosis-associated proteins, including $\mathrm{p} 53$, cyclin-dependent kinase $11^{\mathrm{p} 60}, \mathrm{Bcl}-2$, $\mathrm{Bcl}-\mathrm{xL}$ and p66Shc, to inhibit apoptosis in various types of tumors $(20,21)$. Mortalin binds to $\mathrm{p} 53$ to form a complex that insulates p53 in the cytoplasm and prevents its transcriptional activation (32). Furthermore, a previous study demonstrated that the downregulation of mortalin expression markedly promoted apoptosis in ICC cell lines (29). This was supported by fact that malignant histopathological features, including lymphatic metastasis, multiple tumors, poor differentiation and high TNM stage, were more frequently observed in high mortalin expression ICC tissues compared with those in low mortalin expression tissues. In view of these results, it is concluded that high expression of mortalin is associated with tumor progression and malignant ICC phenotypes, and may be a prognostic indicator for ICC patients.

In the present study, Bcl-2 expression was markedly increased in ICC tissues compared with adjacent peritumoral tissues. The expression of Bax was significantly decreased in ICC tissues. Furthermore, the expression of mortalin in ICC patients was positively correlated with the expression of Bcl-2 and negatively correlated with the expression of Bax. Multiple linear regression analysis also indicated a close association between mortalin and $\mathrm{Bcl}-2$ expression in ICC patient tissues. High expression of Bcl-2 and low expression of Bax were demonstrated to be associated with malignant phenotypes, which may be due to the role of Bcl-2 and Bax in the intrinsic apoptotic pathway. It has been previously indicated that the interaction of $\mathrm{Bcl}-2$ and $\mathrm{Bcl}-\mathrm{xL}$ with mortalin interferes with mortalin-p53 interaction, inactivating p53 function and inducing cancer cell apoptosis (21). Activation of p53 can trigger the activation of pro-apoptotic genes, including Bax (33), and allows mitochondrial proteins, such as $\mathrm{Bcl}-2$, to regulate apoptosis (34). The overexpression of mortalin directly abrogates the transcriptional activation of p53 (35). Further investigation regarding the associations between mortalin and $\mathrm{Bcl}-2$ or Bax in patients with ICC would be beneficial to improve therapeutic strategy and to identify prognostic markers. Importantly, ICC patients expressing a low level of Bax or a high level of Bcl-2 were associated with a relatively poor prognosis.

Cox regression analysis indicated that $\mathrm{Bcl}-2$ was an independent predictor of ICC prognosis, while Bax was not suitable as a predictor. Evaluation of the combinatorial effects of the 3 markers revealed that the subgroup presenting with high mortalin and Bcl-2 expression and low Bax expression had the worst prognosis of all ICC patients examined. However, the present study was limited by only investigating ICC tissues from patients who were diagnosed and treated at a single hospital.

In conclusion, mortalin and Bcl-2 overexpression and/or the low expression of Bax are implicated in the anti-apoptotic effect and tumor progression of ICC. Mortalin or Bcl-2 expression, or a combination of mortalin, Bcl-2 and Bax expression may be used to predict the prognosis of ICC, as well as being potential therapeutic targets.

\section{Acknowledgements}

This study was supported by the National Natural Science Foundation of China (grant nos. 81260084 and 81472840), the Scientific Research Foundation of the Education Department of Yunnan Province (grant no. 2017YJS079) and the Alliance Special Foundation of Kunming Medical University (grant no. 2015FB056).

\section{References}

1. Rahnemai-Azar AA, Weisbrod AB, Dillhoff M, Schmidt C and Pawlik TM: Intrahepatic cholangiocarcinoma: Current management and emerging therapies. Expert Rev Gastroenterol Hepatol 11: 439-449, 2017.

2. Lubezky N, Facciuto M, Harimoto N, Schwartz ME and Florman SS: Surgical treatment of intrahepatic cholangiocarcinoma in the USA. J Hepatobiliary Pancreat Sci 22: 124-130, 2015.

3. Yamashita S, Koay EJ, Passot G, Shroff R, Raghav KP, Conrad C, Chun YS, Aloia TA, Tao R, Kaseb A, et al: Local therapy reduces the risk of liver failure and improves survival in patients with intrahepatic cholangiocarcinoma: A comprehensive analysis of 362 consecutive patients. Cancer 123: 1354-1362, 2017. 
4. Buettner S, van Vugt JL, IJzermans JN and Groot Koerkamp B: Intrahepatic cholangiocarcinoma: Current perspectives. Onco Targets Ther 10: 1131-1142, 2017.

5. Zhang H, Yang T, Wu M and Shen F: Intrahepatic cholangiocarcinoma: Epidemiology, risk factors, diagnosis and surgical management. Cancer Lett 379: 198-205, 2016.

6. Oliveira DV, Zhang S, Chen X, Calvisi DF and Andersen JB Molecular profiling of intrahepatic cholangiocarcinoma: The search for new therapeutic targets. Expert Rev Gastroenterol Hepatol 11: 349-356, 2017.

7. Si A, Li J, Xing X, Lei Z, Xia Y, Yan Z, Wang K, Shi L and Shen F: Effectiveness of repeat hepatic resection for patients with recurrent intrahepatic cholangiocarcinoma: Factors associated with long-term outcomes. Surgery 161: 897-908, 2017.

8. Reed JC: Bcl-2 and the regulation of programmed cell death. J Cell Biol 124: 1-6, 1994.

9. Hatok J and Racay P: Bcl-2 family proteins: Master regulators of cell survival. Biomol Concepts 7: 259-270, 2016

10. Thomas S, Quinn BA, Das SK, Dash R, Emdad L, Dasgupta S, Wang XY, Dent P, Reed JC, Pellecchia M, et al: Targeting the Bcl-2 family for cancer therapy. Expert Opin Ther Targets 17: 61-75, 2013.

11. Kelly PN and Strasser A: The role of Bcl-2 and its pro-survival relatives in tumourigenesis and cancer therapy. Cell Death Differ 18: 1414-1424, 2011.

12. Ermiah E, Buhmeida A, Khaled BR, Abdalla F, Salem N, Pyrhönen S and Collan Y: Prognostic value of bcl-2 expression among women with breast cancer in Libya. Tumour Biol 34: 1569-1578, 2013.

13. Casneuf VF, Fonteyne P, Van Damme N, Demetter P, Pauwels P, de Hemptinne B, De Vos M, Van de Wiele C and Peeters M: Expression of SGLT1, Bcl-2 and p53 in primary pancreatic cancer related to survival. Cancer Invest 26: 852-859, 2008.

14. Brady HJ and Gil-Gómez G: Bax. The pro-apoptotic Bcl-2 family member, Bax. Int J Biochem Cell Biol 30: 647-650, 1998.

15. Liu Z, Ding Y, Ye N, Wild C, Chen H and Zhou J: Direct activation of bax protein for cancer therapy. Med Res Rev 36: 313-341, 2016.

16. Gross A, Jockel J, Wei MC and Korsmeyer SJ: Enforced dimerization of BAX results in its translocation, mitochondrial dysfunction and apoptosis. EMBO J 17: 3878-3885, 1998.

17. Wadhwa R, Kaul SC, Ikawa Y and Sugimoto Y: Identification of a novel member of mouse hsp70 family. Its association with cellular mortal phenotype. J Biol Chem 268: 6615-6621, 1993.

18. Kaul SC, Deocaris CC and Wadhwa R: Three faces of mortalin: A housekeeper, guardian and killer. Exp Gerontol 42: 263-274, 2007.

19. Wadhwa R, Yaguchi T, Hasan MK, Mitsui Y, Reddel RR and Kaul SC: Hsp70 family member, mot-2/mthsp70/GRP75, binds to the cytoplasmic sequestration domain of the p53 protein. Exp Cell Res 274: 246-253, 2002

20. Londono C, Osorio C, Gama V and Alzate O: Mortalin, apoptosis, and neurodegeneration. Biomolecules 2: 143-164, 2012.

21. Saxena N, Katiyar SP, Liu Y, Grover A, Gao R, Sundar D, Kaul SC and Wadhwa R: Molecular interactions of Bcl-2 and Bcl-xL with mortalin: Identification and functional characterization. Biosci Rep 33: e00073, 2013.

22. Na Y, Kaul SC, Ryu J, Lee JS, Ahn HM, Kaul Z, Kalra RS, Li L, Widodo N, Yun CO and Wadhwa R: Stress chaperone mortalin contributes to epithelial-mesenchymal transition and cancer metastasis. Cancer Res: Mar 9, 2016 (Epub ahead of print).
23. Cui X, Li Z, Piao J, Li J, Li L, Jin A and Lin Z: Mortalin expression in pancreatic cancer and its clinical and prognostic significance. Hum Pathol 64: 171-178, 2017.

24. Sun J, Che SL, Piao JJ, Xu M, Chen LY and Lin ZH: Mortalin overexpression predicts poor prognosis in early stage of non-small cell lung cancer. Tumour Biol 39: 1010428317695918, 2017.

25. Huang XY, Zhang C, Cai JB, Shi GM, Ke AW, Dong ZR, Zhang PF, Fan J, Peng BG and Zhou J: Comprehensive multiple molecular profile of epithelial mesenchymal transition in intrahepatic cholangiocarcinoma patients. PLoS One 9: e96860, 2014.

26. Talwalkar JA, Seaberg E, Kim WR and Wiesner RH: Predicting clinical and economic outcomes after liver transplantation using the Mayo primary sclerosing cholangitis model and Child-Pugh score. National institutes of diabetes and digestive and kidney diseases liver transplantation database group. Liver Transpl 6: 753-758, 2000

27. Wittekind C: Pitfalls in the classification of liver tumors. Pathologe 27: 289-293, 2006 (In German).

28. Edge SB and Compton CC: The American Joint Committee on Cancer: The 7th edition of the AJCC cancer staging manual and the future of TNM. Ann Surg Oncol 17: 1471-1474, 2010.

29. Kang Q, Cai JB, Dong RZ, Liu LX, Zhang C, Zhang PF, Zou H, Xie N, Zhang L, Zhang XY, et al: Mortalin promotes cell proliferation and epithelial mesenchymal transition of intrahepatic cholangiocarcinoma cells in vitro. J Clin Pathol 70: 677-683, 2017.

30. Chen J, Liu WB, Jia WD, Xu GL, Ma JL, Huang M, Deng YR and Li JS: Overexpression of Mortalin in hepatocellular carcinoma and its relationship with angiogenesis and epithelial to mesenchymal transition. Int J Oncol 44: 247-255, 2014.

31. Ando K, Oki E, Zhao Y, Ikawa-Yoshida A, Kitao H, Saeki H, Kimura Y, Ida S, Morita M, Kusumoto T and Maehara Y: Mortalin is a prognostic factor of gastric cancer with normal p53 function. Gastric Cancer 17: 255-262, 2014.

32. Wadhwa R, Takano S, Robert M, Yoshida A, Nomura H, Reddel RR, Mitsui $\mathrm{Y}$ and Kaul SC: Inactivation of tumor suppressor p53 by mot-2, a hsp70 family member. J Biol Chem 273: 29586-29591, 1998.

33. Zhang J, Huang K, O'Neill KL, Pang X and Luo X: Bax/Bak activation in the absence of Bid, Bim, Puma, and p53. Cell Death Dis 7: e2266, 2016.

34. Galluzzi L, Morselli E, Kepp O, Tajeddine N and Kroemer G: Targeting p53 to mitochondria for cancer therapy. Cell Cycle 7: 1949-1955, 2008

35. Grover A, Priyandoko D, Gao R, Shandilya A, Widodo N, Bisaria VS, Kaul SC, Wadhwa R and Sundar D: Withanone binds to mortalin and abrogates mortalin-p53 complex: Computational and experimental evidence. Int J Biochem Cell Biol 44: 496-504, 2012.

This work is licensed under a Creative Commons Attribution-NonCommercial-NoDerivatives 4.0 International (CC BY-NC-ND 4.0) License. 